\title{
Bomb Atoms in Modern Honey Reveal a Regional Soil Control on Pollutant Cycling by Plants
}

James Kaste ( $\square$ jmkaste@wm.edu )

William \& Mary

\section{Paul Volante}

William \& Mary

Andrew Elmore

University of Maryland Center for Environmental Science https://orcid.org/0000-0002-9697-9457

\section{Article}

Keywords: Bomb atoms, Plants, Soil control, Pollutant cycling

Posted Date: September 28th, 2020

DOI: https://doi.org/10.21203/rs.3.rs-57710/v1

License: (1) This work is licensed under a Creative Commons Attribution 4.0 International License.

Read Full License

Version of Record: A version of this preprint was published at Nature Communications on March 29th, 2021. See the published version at https://doi.org/10.1038/s41467-021-22081-8. 


\title{
Bomb atoms in modern honey reveal a regional soil control on pollutant cycling by plants
}

\author{
J.M. Kaste ${ }^{1 *}$, P. Volante ${ }^{1}$, \& A.J. Elmore 2,3 \\ ${ }^{1}$ Geology Department, William \& Mary, Williamsburg VA, USA \\ ${ }^{2}$ Unviersity of Maryland Center for Environmental Science, Frostburg, MD, USA \\ ${ }^{3}$ National Socio-Environmental Synthesis Center, Annapolis MD, USA \\ *e-mail: jmkaste@wm.edu
}

One of the longer-lived and more dangerous fission products dispersed globally by mid-20 century atmospheric nuclear weapons testing was ${ }^{137} \mathrm{Cs}$, which has a 30-year radioactive halflife. It has generally been assumed that outside the vicinity of the test sites, ${ }^{137}$ Cs fallout washed off vegetation and was immobilized by soil, and thus of no ecological concern. Here we show that native plants thousands of kilometers from testing sites continue to cycle ${ }^{137} \mathrm{Cs}$ because it mimics the essential nutrient potassium, and consequently, bees magnify this potentially lethal radionuclide in honey. There were no atmospheric weapons tests in the eastern United States, but, most honey here has detectable ${ }^{137} \mathrm{Cs}$ at $>0.03 \mathrm{~Bq} \mathrm{~kg}^{-1}(\sim 1$ million atoms per tablespoon), and in the southeastern U.S. it can be over 500 times higher. By measuring honey, we show regional patterns in the biogeochemical cycling of ${ }^{137} \mathrm{Cs}$ for the first time and conclude that plants and animals receive disproportionally high exposure to ionizing radiation from ${ }^{137} \mathrm{Cs}$ in soils with low potassium. In several cases, the presence of ${ }^{137} \mathrm{Cs}$ more than doubled the ionizing radiation from gamma rays and $\mathrm{x}$-rays in the honey, indicating that despite its radioactive half-life, the environmental danger to honeybees from this fission product can persist for more than six decades.

During the middle of the $20^{\text {th }}$ century, five countries tested over 500 nuclear weapons in the air, which, taken together released far more ionizing radiation to the atmosphere than any other event or combination of events in human history ${ }^{1,2}$. The majority of these weapons were detonated in just a few locations in the northern hemisphere; the Marshall Islands in the Pacific Ocean (U.S.) and Novaya Zemlya (former U.S.S.R.) hosted over half of the energy yield of all the tests ${ }^{3}$. Many of the air detonations were so powerful that dozens of radioactive fission products (e.g. ${ }^{137} \mathrm{Cs},{ }^{90} \mathrm{Sr},{ }^{131} \mathrm{I}$ ) were injected into the stratosphere and distributed globally with a residence time of ca. 1 year before deposition primarily by rainfall. In 1963, the Nuclear Test Ban Treaty effectively limited atmospheric testing with the exception of a few dozen smaller yield detonations that occurred primarily in China and Africa in the 1960s and 1970s ${ }^{1}$. The presence of radioactive pollution from nuclear testing is globally ubiquitous, and is detectable on every continent and even in deep ocean trenches ${ }^{4}$. Earth scientists widely apply the "bomb spike" radionuclides as a global chronological maker based on the assumption of strong radionuclide associations with minerals, and there are thousands of published studies using weapons fallout to trace soil transport and for dating sediments 
deposited in the $1960 \mathrm{~s}^{5,6}$. The negative consequences of global nuclear fallout to human health are just recently coming into focus ${ }^{7,8}$, but the long-term biogeochemical fate and ecological consequences of radioactive pollution from weapons tests in ecosystems outside the immediate vicinity of test sites has not been carefully evaluated.

While most of the radiation produced by a nuclear weapon detonation decays within the first few days, one of the longest-lived and more abundant fission products is ${ }^{137} \mathrm{Cs}$, which has a half-life of 30.2 years. During radioactive decay to stable ${ }^{137} \mathrm{Ba},{ }^{137} \mathrm{Cs}$ atoms emit ionizing radiation, including beta particles with $\mathrm{E}_{\max }=0.512 \mathrm{MeV}, \mathrm{Ba} \mathrm{K} \alpha$ x-rays at $0.032 \mathrm{MeV}$, and a $0.662 \mathrm{MeV}$ gamma ray, and recent research shows that even low amounts of ${ }^{137} \mathrm{Cs}$ can kill organisms and disrupt essential ecosystem services ${ }^{9-14}$. Cesium is not required for plant growth and functioning ${ }^{15}$. However, because $\mathrm{Cs}$ has a similar ionic charge and radius as $\mathrm{K}$, an essential element for plants, ${ }^{137} \mathrm{Cs}$ is absorbed from the soil via $\mathrm{K}$ specific membrane transporters in vegetation ${ }^{16,17}$. This pathway for

${ }^{137} \mathrm{Cs}$ from soils to plants and into the human diet was predicted decades ago, leading to a government supported radionuclide surveillance program that conducted widespread testing of milk in the late 1950s-1980s ${ }^{18,19}$. However, there is no published research documenting the presence or absence of ${ }^{137} \mathrm{Cs}$ in eastern U.S. plants or in the U.S. food supply since $1988^{20}$. Here we present the first measurements of ${ }^{137} \mathrm{Cs}$ in honey sourced from the eastern U.S. and leverage this with a highresolution dataset of soil potassium which gives us the power to show regional patterns in the biogeochemical cycling of this dangerous radionuclide. We find that soil-plant-pollinator focusing effects can magnify ${ }^{137} \mathrm{Cs}$ by several orders of magnitude in honey sourced from specific physiographic regions with low soil $\mathrm{K}$.

\section{${ }^{137} \mathrm{Cs}$ in eastern U.S. honey}

Honey is produced by wild and managed pollinators across the world, and, because bees make this product by reducing the water content of flower-derived nectar by nearly 5 -fold, environmental contaminants are naturally concentrated in this food ${ }^{21}$. Using low background gamma spectrometry we found detectable ${ }^{137} \mathrm{Cs}\left(\geq 0.03 \mathrm{~Bq}^{137} \mathrm{Cs} \mathrm{kg}^{-1}=10^{5.94}\right.$ atoms tablespoon $\left.{ }^{-1}\right)$ in 68 of 122 honey samples sourced from North America. Most of these samples came from private small-scale eastern U.S. honey producers where we identified the hive locations at the U.S. county scale (110 samples), for which average soil $\mathrm{K}$ concentration and ${ }^{137} \mathrm{Cs}$ deposition rates are available ${ }^{22,23}$ (Fig.1).

Atmospheric deposition models and direct soil measurements show that the northeastern United States received slightly higher burdens of ${ }^{137} \mathrm{Cs}$ from the weapons tests than the southeastern United States ${ }^{1,24}$. Surprisingly, the geographic pattern of ${ }^{137} \mathrm{Cs}$ in honey is not correlated with this regional gradient of fallout $\left(\mathrm{r}^{2}<.01 ; \mathrm{p}>0.5\right)$. Of 40 honey samples collected from U.S. states north of Virginia, only 12 had detectable ${ }^{137} \mathrm{Cs}$, but 36 of 39 honey samples from Florida, Georgia, and South Carolina had detectable ${ }^{137} \mathrm{Cs}$ (Fig.1). For comparison to the east coast samples, we analyzed 5 honeys from larger commercial operations in the central U.S. where the hives were located primarily on croplands. These honeys were very low in ${ }^{137} \mathrm{Cs}$, with 4 undetectable samples and one sample just at the detection limit, and a single sample from Cuba had undetectable ${ }^{137} \mathrm{Cs}$. 


\section{a}

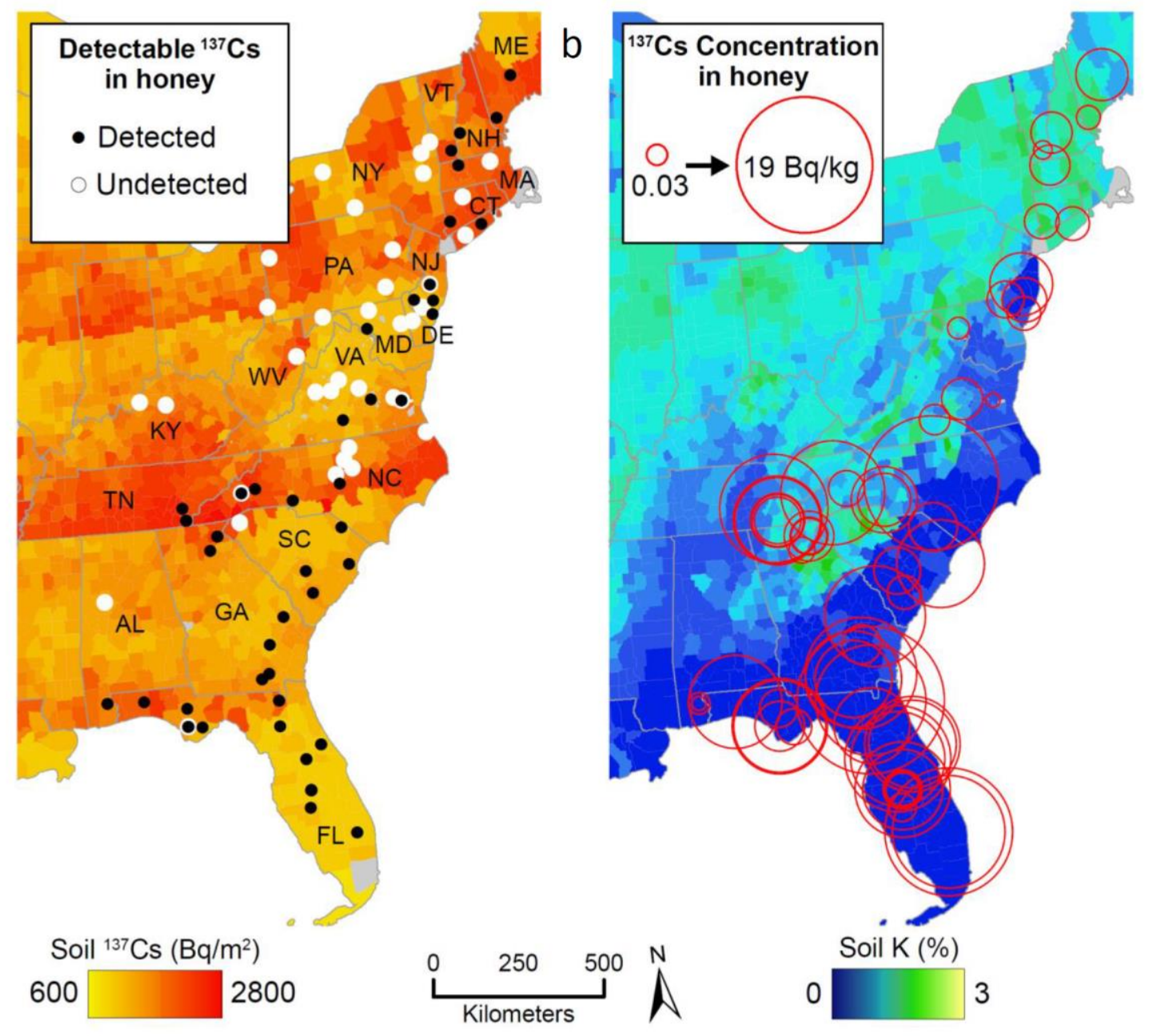

Fig. 1. Distribution of ${ }^{137} \mathrm{Cs}$ activities in honey in the eastern United States. (a) Detectable ${ }^{137} \mathrm{Cs}$ in honey on a map with $20^{\text {th }}$ century ${ }^{137} \mathrm{Cs}$ deposition to soils determined at the county scale ${ }^{22,24}$ decay corrected to 2019. (b) Circles scaled logarithmically showing the relative magnitude of ${ }^{137} \mathrm{Cs}$ in honey on a map with county mean soil potassium concentrations determined from airborne radiometric surveys ${ }^{23}$.

While soils of the eastern U.S. have a relatively narrow range of 1 to $2 \mathrm{kBq}^{137} \mathrm{Cs} \mathrm{m}^{-2}$, concentrations in honey from this region spanned nearly 3 orders of magnitude with far higher levels in the southeast (Fig. 1b). We find an inverse relationship between the transfer of ${ }^{137} \mathrm{Cs}$ from soils to honey and mean soil $\mathrm{K}$ concentrations of the county from it was sourced $\left(\mathrm{r}^{2}=0.363 ; \mathrm{p}<\right.$ 0.001; Fig. 2). The southeastern U.S. has relatively old, intensely weathered and leached soils from the warm and wet climate on coastal plain geology, tending to be deficient in phosphorous, $\mathrm{K}$, and other rock-derived nutrients ${ }^{25}$. In contrast, recent glaciation in the northeastern U.S. and freshly exposed bedrock in the Appalachian Highlands maintains a relatively large supply of $\mathrm{K}^{26}$. These climate and soil parent material factors create a natural gradient of soil $\mathrm{K}$ that subsequently drives a regional control on ${ }^{137} \mathrm{Cs}$ in honey, but agriculture causes local exceptions. Four of the honeys from FL that were specifically identified as sourced from managed orange groves or pepper crops, where 
$\mathrm{K}$ and $\mathrm{N}$ amendments are common were much lower in ${ }^{137} \mathrm{Cs}$ than FL wildflower honeys, which is consistent with our observations that agricultural honeys from the central U.S. tended to be low in ${ }^{137}$ Cs. Physiological differences across plant families also cause variations in Cs uptake ${ }^{27}$, which likely impact our observations, but our hypothesis that soil $\mathrm{K}$ is the first-order regional control on the ${ }^{137} \mathrm{Cs}$ content of honey is well supported by experimental-based research on Cs biogeochemistry ${ }^{15,17}$.

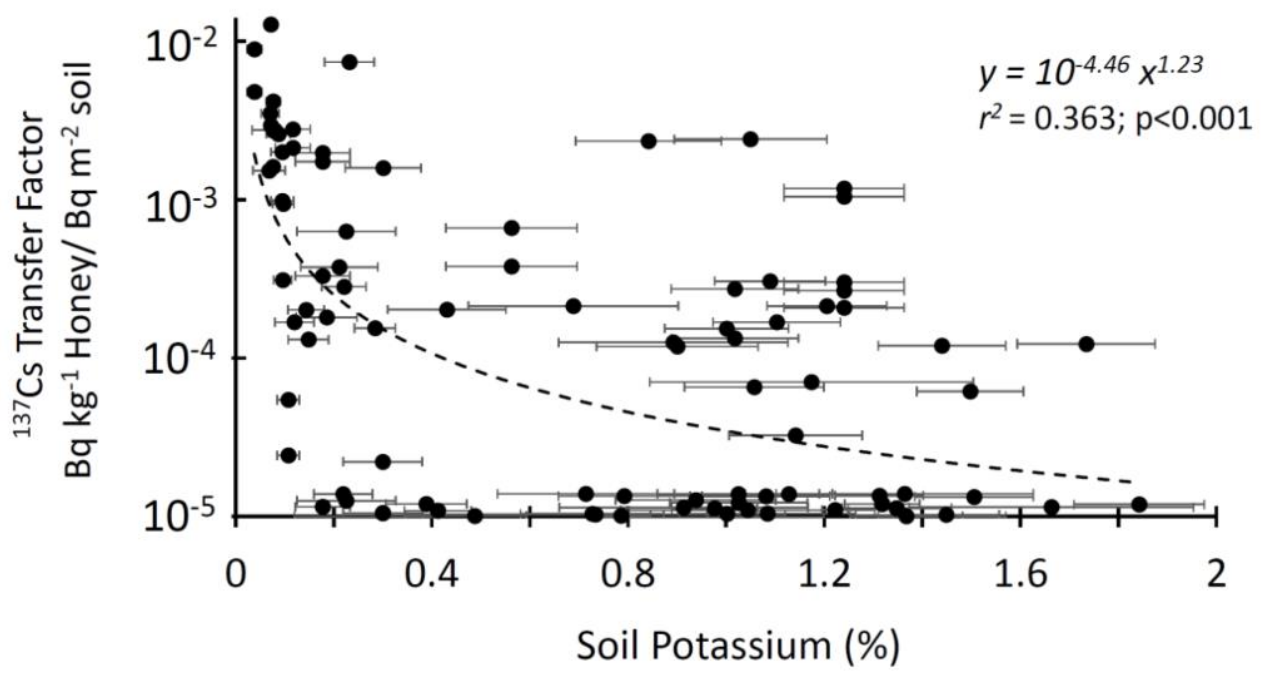

Fig. 2. The transfer of ${ }^{137} \mathrm{Cs}$ from soil to honey scales inversely with the average soil $\mathrm{K}$ of the county from which it is sourced. Uncertainty on this scaling is dominated by soil $\mathrm{K}$ variability within each county, shown here as one standard deviation of the mean.

\section{Soil potassium inhibits ${ }^{137} \mathrm{Cs}$ uptake by vegetation}

Soil $\mathrm{K}$ depresses ${ }^{137} \mathrm{Cs}$ uptake by plants and ultimately limits this radionuclide in vegetation via several mechanisms. Experiments using a range of plant species indicate that Cs is not required by vegetation and thus never preferentially absorbed over $\mathrm{K}$, rather, the $\mathrm{Cs}$ is taken because its ionic properties are near enough to $\mathrm{K}$ to allow mobility through $\mathrm{K}$ transport channels ${ }^{15-17}$. Increasing available K simply reduces Cs uptake due to the mass action relationships associated with plant-soil cation exchange reactions, thus K-based fertilizers are a proven method to reduce ${ }^{137} \mathrm{Cs}$ uptake by food crops in heavily contaminated soils ${ }^{28}$. The ammonium ion $\left(\mathrm{NH}_{4}{ }^{+}\right)$also competes with $\mathrm{Cs}$ in these reactions, further explaining why honey sourced from managed agricultural systems tended to be very low in ${ }^{137} \mathrm{Cs}$. Kinetic controls on Cs uptake reactions may shift significantly at a threshold of $\mathrm{K}$ given that higher absorption rates by vegetation are observed in $\mathrm{K}$ limited soil ${ }^{16}$. Our measurements support a threshold model of ${ }^{137} \mathrm{Cs}$ uptake into plants, given that all 26 honey samples collected from counties with soil $\mathrm{K}<0.17 \%$ had detectable ${ }^{137} \mathrm{Cs}$, which included honey from 4 different U.S. States (Fig. 2). Moreover, soil mineralogy likely plays an important role in sequestering ${ }^{137} \mathrm{C}$ s from plants. Soils high in $\mathrm{K}$ tend to have illite, a family of clay minerals with a strong capacity to absorb or include $\mathrm{Cs}$, thereby reducing its bioavailability ${ }^{29}$. While the mechanisms limiting plant uptake of ${ }^{137} \mathrm{Cs}$ have been demonstrated experimentally, our analyses of honey show 
how these processes play out regionally, controlling how plants and pollinators are exposed to widely varying degrees of radioactive pollution because of local soil nutrient status.

The assumption that ${ }^{137} \mathrm{Cs}$ is strongly fixed to soil and sediments forms the basis for its widespread use as sediment tracing and dating tool by earth scientists ${ }^{6,30}$. Thus, there is an absence of studies documenting the uptake of this fission product by native plants and possible pathways to the food supply in North America. One exception to this is the Pasteurized Milk Network (PMN), started in 1957 by the U.S. Public Health Service. Milk and honey are similar in that each is produced by foraging animals in every U.S. State, but in the 1950s, milk was considered the most likely pathway for nuclear fallout to enter the U.S. food supply. Consequently, a surveillance program sampled milk at central processing plants to monitor the radionuclide content, beginning with stations in five major cities ${ }^{18}$, but expanding with individual state programs to include over 100 stations in the 1960s. With the PMN and individual state programs joining the efforts using the same methodology, over 10,000 measurements of ${ }^{137} \mathrm{Cs}$ in milk are available, including monthly measurements from nearly every U.S. State for 1960 to $1975^{19,31}$. These data track the biological uptake of fission products from soil to vegetation to milk in different regions of North America and are valuable to compare with our more recent measurements of ${ }^{137} \mathrm{Cs}$ in honey.

Nationwide monthly average ${ }^{137} \mathrm{Cs}$ concentrations in milk peaked in late 1963 at $6 \mathrm{~Bq} \mathrm{~kg}^{-1}$ and fell sharply to $<0.6 \mathrm{~Bq} \mathrm{~kg}^{-1}$ by 1970 in response to the Nuclear Test-Ban Treaty ${ }^{19}$. Of the 122 honey samples we measured recently, three exceeded $6 \mathrm{~Bq} \mathrm{~kg}^{-1}$, and 30 exceeded the $0.5 \mathrm{~Bq} \mathrm{~kg}^{-1}$ concentration that nationwide average milk remained below after 1970 . The highest honey ${ }^{137} \mathrm{Cs}$ concentration that we measured from Florida in 2018 exceeded any reported monthly milk ${ }^{137} \mathrm{Cs}$ value between 1958 and 2014, when the program formally ended (Fig. 3), indicating that honey can be highly concentrated in ${ }^{137} \mathrm{Cs}$ compared with other foods. The geographic pattern of ${ }^{137} \mathrm{Cs}$ reported by the PMN is consistent with the pattern we find in honey today. Nearly every month between 1960 and 2014, the sampling stations in FL reported the highest ${ }^{137}$ Cs concentrations in milk compared with the rest of the United States. The ${ }^{137} \mathrm{Cs}$ content of milk from FL had a delayed decline compared with NY area milk after 1963, and average honey ${ }^{137}$ Cs today in FL is significantly higher than average NY area honey (Fig. 3). Median soil K in FL was about 0.1\%, compared with $1.3 \%$ in the NY area. Our data taken together with the PMN dataset show that plants growing in $\mathrm{K}$ deficient soils of the southeastern U.S. are more prone to absorbing ${ }^{137} \mathrm{Cs}$ decades after atmospheric deposition, and that this contamination is transferred to foods by animal foragers. 


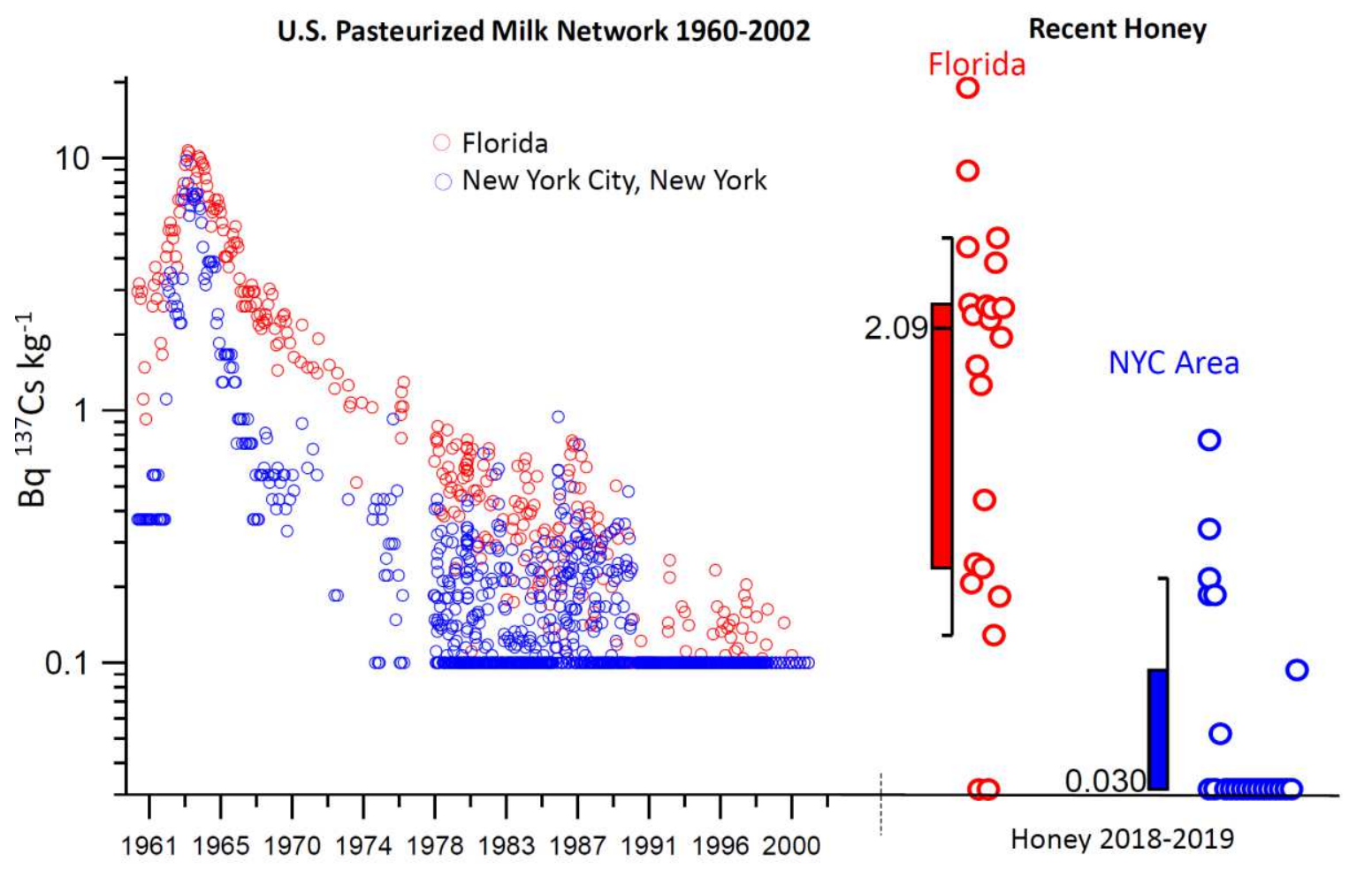

Fig. 3. Monthly concentrations of ${ }^{137} \mathrm{Cs}$ in milk measured by the U.S. Public Health Service radionuclide surveillance program from 1960 through 2002 in Tampa, Florida and New York City (NYC) compared with recent honey from Florida and the NYC area ${ }^{19,31}$. Honey ${ }^{137} \mathrm{Cs}$ concentrations are shown on the same scale, median values for each area's honey are given; these two regions have significantly different magnitudes of ${ }^{137} \mathrm{Cs}$ contamination (Mann-Whitney z score: 4.70, $\mathrm{p}<0.001)$ Detection limit is 0.1 and $0.03 \mathrm{~Bq}^{137} \mathrm{Cs} \mathrm{kg}^{-1}$ for the milk and honey data, respectively. Only 7 of the $21 \mathrm{NYC}$ area (includes CT, NJ) honeys had detectable ${ }^{137} \mathrm{Cs}$.

To further investigate the widespread biogeochemical cycling of ${ }^{137} \mathrm{Cs}$ from regional weapons pollution, we analyzed vegetation archives from the Hubbard Brook Experimental Forest (HBEF) and more recent collections to reconstruct ${ }^{137} \mathrm{Cs}$ in native plants in the eastern U.S. over the last 50 years (Fig. 4). The HBEF one of the world's longest running ecosystem studies and maintains an archive of native foliage collected as early as the 1960s from several different northeastern states. These data show clearly that vegetation across multiple common species in the eastern U.S. has been declining in ${ }^{137} \mathrm{Cs}$. At its peak, however, the levels in vegetation during the 1960 s through the $1980 \mathrm{~s}$ were extremely high, at 500 to over $1000 \mathrm{~Bq} \mathrm{~kg}^{-1}$, which is orders of magnitude higher than levels known to be dangerous for insects to digest ${ }^{9,13,14}$. ${ }^{137} \mathrm{Cs}$ in vegetation declines from a median value of $390 \mathrm{~Bq} \mathrm{~kg}^{-1}$ in the late 1960 s to approximately $4 \mathrm{~Bq} \mathrm{~kg}^{-1}$ in 2019 , which is 2 orders of magnitude. The more high-resolution time series of ${ }^{137} \mathrm{Cs}$ in milk (Fig. 3) shows similar scales of decline, from a 1963 high of $10.7 \mathrm{~Bq} \mathrm{~kg}^{-1}$ in Tampa, F.L. and $9.8 \mathrm{~Bq} \mathrm{~kg}^{-1}$ in N.Y. to values very near the $0.1 \mathrm{~Bq} \mathrm{~kg}^{-1}$ PMN detection limit in both areas by 2010. These data taken together show how the biological uptake of ${ }^{137} \mathrm{Cs}$ from soils declines significantly over time, as the radionuclide undergoes radioactive decay, but also as the ${ }^{137} \mathrm{Cs}$ migrates down beneath the active plant rooting depth ${ }^{5}$. If the ${ }^{137} \mathrm{Cs}$ 
content of honey followed a similar trend as milk (Fig. 3) and foliage (Fig. 4) then average ${ }^{137} \mathrm{Cs}$ in honey in the Southeastern U.S. (GA, FL, SC, NC) would have been far over $100 \mathrm{~Bq} \mathrm{~kg}^{-1}$ in the 1960s-1970s, which even exceeds most national concentration standards for human consumption ${ }^{32}$.

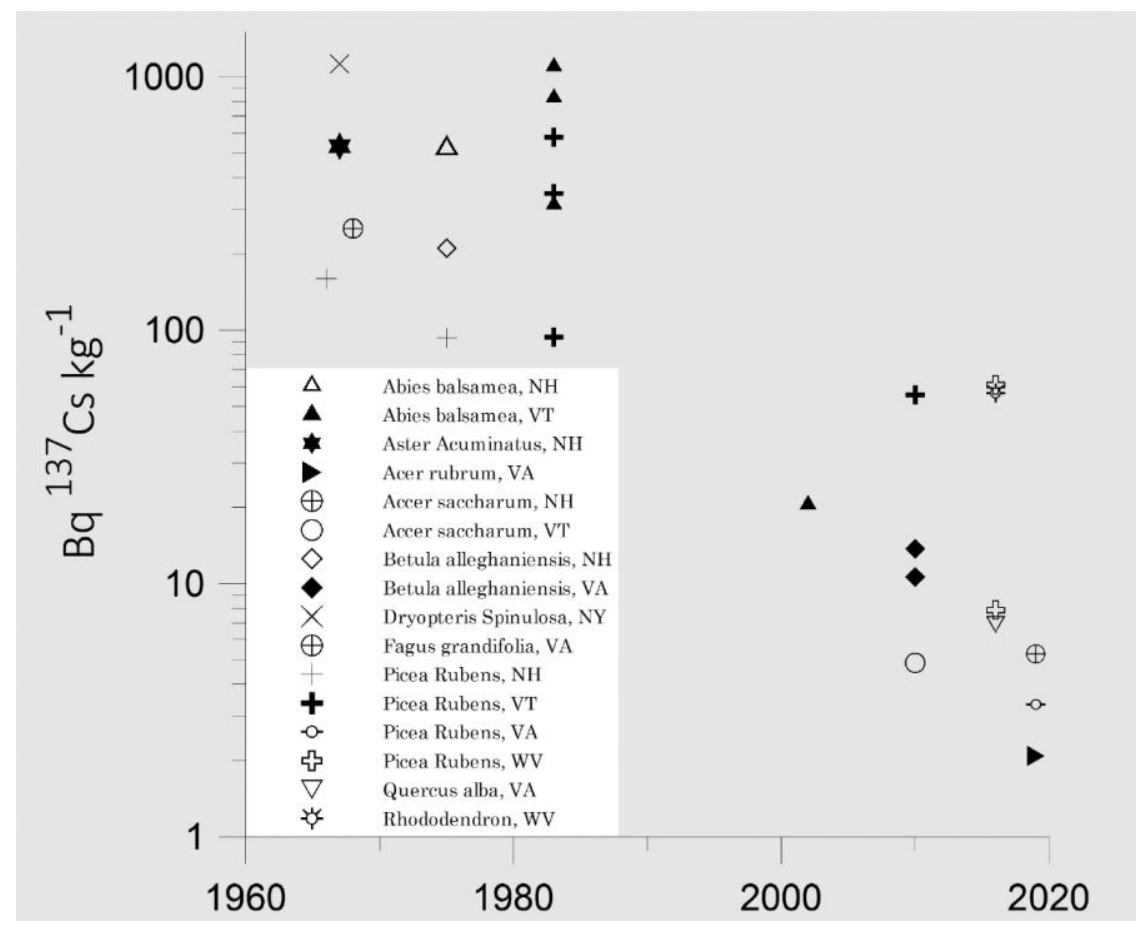

Fig. 4. The ${ }^{137}$ Cs content of native vegetation (foliage) from the eastern U.S. using archives and more recent collections. Each symbol represents a single plant, and the species and state are given in the legend.

\section{A long and dangerous legacy from the bombs}

While the concentrations of ${ }^{137} \mathrm{Cs}$ we report in honey today are well below the $50-100 \mathrm{~Bq} \mathrm{~kg}^{-1}$ dietary threshold level of concern observed by many countries ${ }^{32}$, and not evidently dangerous for human consumption, the widespread residual radiation from 0.03 to $19.1 \mathrm{~Bq}^{137} \mathrm{Cs} \mathrm{kg}^{-1}$ is surprising given that 2 half-lives have elapsed since most of the bomb production of ${ }^{137} \mathrm{Cs}$. All life on earth has naturally occurring sources of alpha, beta, and gamma radiation. The dominant naturally occurring source of gamma-radiation in plants and most foods is ${ }^{40} \mathrm{~K}$, which we measured concurrently with ${ }^{137} \mathrm{Cs}$. In 34 cases, ionizing radiation sourced from the ${ }^{137} \mathrm{Cs}$ accounted for more than $20 \%$ of the $\mathrm{x}$ ray and gamma radiation from the honey, and, in 13 cases (ca. 11\%), ${ }^{137} \mathrm{Cs}$ contamination more than doubled the total the $\mathrm{x}$-ray and gamma-ray radiation of the sample. Research emerging in the last decade from two different continents shows that small amounts of ${ }^{137} \mathrm{Cs}$ pollution can be lethal to pollinating insects and cause measurable damage to surrounding ecosystems ${ }^{10,14}$. Given that increased exposure to ionizing radiation comes with increased risk for DNA damage in plants, insects, and humans, the magnification of ${ }^{137} \mathrm{Cs}$ in honey should be carefully considered as a major past and current threat to honeybee health ${ }^{33,34}$. 
Experiments with the Pale Blue Grass Butterfly, Zizeeria maha indicate a linear dose-dependent response in deformations and mortality when the insects eat vegetation ranging from 2.5 to $48 \mathrm{~Bq}$ Cs $\mathrm{kg}^{-1}$ in Japan ${ }^{13,14}$. A significant fraction of honey samples collected from the southeastern United States (16 out of 49 south of VA) fell in this range in 2018-2019, and decades ago it must have been far higher. It is important to note that because radiocesium emits penetrating beta particles and gamma rays, honeybee exposure to increased ionizing radiation comes from both consuming polluted honey and from residing in a hive in close proximity to 10 to $20 \mathrm{~kg}$ of radioactive honey for most of the day. Populations of pollinating butterflies and bumblebees across a ${ }^{137} \mathrm{Cs}$ pollution gradient near the Chernobyl Nuclear Power Plant in the Ukraine are significantly reduced at even the lowest incremental exposure increases between 0.01 and $0.1 \mu \mathrm{S} \mathrm{hr}{ }^{-1}$. As the pollinator abundance declines around Chernobyl, significant impacts on ecosystem functioning have been quantified through reductions in fruit production and tree recruitment ${ }^{10}$. These studies taken together indicate that when radioactive pollution doubles the ionizing radiation dose to pollinating insects, as we find that ${ }^{137} \mathrm{Cs}$ in today's honey does in low potassium regions, significant impacts on insect health and declines in ecosystem functioning are predicted.

Several long-standing international agreements on nuclear nonproliferation and arms control have been dismantled in recent years, and some leaders have begun to put increased emphasis on the role of nuclear weapons in military strategies ${ }^{35}$. These developments may lead to renewed weapons testing activities by the nine nuclear capable nations and could encourage other nations to begin testing programs of their own. Our study indicates that vegetation far from a nuclear detonation site can cycle one of the most abundant and dangerous fission products for more than six decades, and in regions of low soil potassium, honeybees get disproportionally high exposure to ionizing radiation from this pollution source. Given that pollinating insects provide vital services to the world's ecosystem and are essential in maintaining global food security ${ }^{36}$, this environmental threat alongside threats to human health should be carefully weighed as policies that control nuclear detonations from testing or military scenarios are formed. 


\section{Materials and Methods}

\section{Analytical Conditions}

122 honey samples were procured from beekeepers as raw, pure and unfiltered. Honey samples were analyzed for radionuclides by directly photon counting 50 to 150 grams of sample using shielded high resolution (peak full-width half-maximum $<1.5 \mathrm{keV}$ at $662 \mathrm{keV}$ ) intrinsic germanium gamma spectrometers for $>150,000$ seconds. Detector efficiency for Canberra 5030 Broad Energy Detectors is determined by counting a certified liquid ${ }^{137} \mathrm{Cs}$ source (Eckert \& Ziegler) and high purity $\mathrm{KCl}$ (Fisher Scientific) for the different counting geometries. We also scanned each honey spectrum for ${ }^{134} \mathrm{Cs}$, a strong gamma emitter at $605 \mathrm{keV}$ and $796 \mathrm{keV}$, which given its short half-life of 2.06 years is a tracer of modern nuclear reactor leakage. Given that there was never a statistically significant photopeak at either $605 \mathrm{keV}$ or $796 \mathrm{keV}$ for any honey sample we conclude that the ${ }^{137} \mathrm{Cs}$ we measure here is predominately legacy nuclear pollution associated with the weapons testing era. Concentrations of ${ }^{137} \mathrm{Cs}$ and ${ }^{40} \mathrm{~K}$ along with two-sigma uncertainties based on counting statistics and baseline subtraction are given in the Supplementary Data Table.

\section{$\underline{\text { Soil Potassium and Cs-137 Data }}$}

In 110 of the 122 samples we identified the locations of the hives at the scale of the U.S. county or counties. Cs-137 fallout depositional fluxes to soils have been calculated from 1953-1972 based on precipitation records and measurements of ${ }^{90} \mathrm{Sr}$ in air and precipitation and match soil records reasonably well ${ }^{3,5,8}$. To determine county-averaged soil potassium, we use a high-resolution soil potassium, dataset determined by airborne radiometric surveys described in detail by the U.S. Geological Survey". For plotting data and statistical tests, "undetected" ${ }^{137}$ Cs samples were assigned a value of $1 / 2$ the detection limit, $=0.015 \mathrm{~Bq}^{137} \mathrm{Cs} \mathrm{kg}^{-1}$.

\section{Data Availability}

All analytical results for ${ }^{137} \mathrm{Cs}$ and ${ }^{40} \mathrm{~K}$ activities in the 122 honey samples are given along with 2sigma analytical uncertainties in Table S1. Soil potassium concentrations and ${ }^{137} \mathrm{Cs}$ deposition for each county is given, along with the standard deviation of the soil county potassium data.

Acknowledgments: We thank the many "citizen scientists" who provided honey samples for this research. We are grateful to David Elmore, Stephen Norton, and Eric Davidson who provided thoughtful feedback on manuscript drafts, Emily Nastase who generated Fig.1, and Steve Simon who provided the ${ }^{137}$ Cs fallout data. We thank Amey Bailey and the Hubbard Brook Experimental Forest for providing access to vegetation archives. This work was funded by a summer research grant from William \& Mary's Provost Office and by a generous faculty award from Joseph Plumeri.

Author contributions: Kaste supervised the project design, sample collection and gamma spectrometry analyses, Volante acquired samples, prepared samples for analysis, and assisted with gamma spectrometry, Elmore executed the geospatial analysis. All three authors assisted with interpretations writing, editing.

Competing interests: Authors declare no competing interests.

Correspondence and requests for materials should be addressed to J.M. Kaste 


\section{References}

1 Beck, H. L. \& Bennettt, B. G. Historical overview of atmospheric nuclear weapons testing and estimates of fallout in the continental United States. Health Physics 82, 591-608, doi:10.1097/00004032-200205000-00007 (2002).

2 Steinhauser, G., Brandl, A. \& Johnson, T. E. Comparison of the Chernobyl and Fukushima nuclear accidents: A review of the environmental impacts. Science of the Total Environment 470, 800817, doi:10.1016/j.scitotenv.2013.10.029 (2014).

3 Simon, S. L., Bouville, A. \& Land, C. E. Fallout from nuclear weapons tests and cancer risks Exposures 50 years ago still have health implications today that will continue into the future. American Scientist 94, 48-57, doi:10.1511/2006.1.48 (2006).

4 Wang, N. et al. Penetration of Bomb C-14 Into the Deepest Ocean Trench. Geophys. Res. Lett. 46, 5413-5419, doi:10.1029/2018gl081514 (2019).

5 Kaste, J. M., Heimsath, A. M. \& Bostick, B. C. Short-term soil mixing quantified with fallout radionuclides. Geology 35, 243-246, doi:10.1130/g23355a.1 (2007).

6 Ritchie, J. C. \& McHenry, J. R. Application of radioactive fallout cesium-137 for measuring soilerosion and sediment accumulation rates and patterns- a review. Journal of Environmental Quality 19, 215-233, doi:10.2134/jeq1990.00472425001900020006x (1990).

7 Gilbert, E. S., Huang, L., Bouville, A., Berg, C. D. \& Ron, E. Thyroid Cancer Rates and I-131 Doses from Nevada Atmospheric Nuclear Bomb Tests: An Update. Radiation Research 173, 659-664, doi:10.1667/rr2057.1 (2010).

8 Simon, S. L. \& Bouville, A. Health effects of nuclear weapons testing. Lancet 386, 407-409, doi:10.1016/s0140-6736(15)61037-6 (2015).

9 Hiyama, A. et al. The Fukushima nuclear accident and the pale grass blue butterfly: evaluating biological effects of long-term low-dose exposures. BMC Evol. Biol. 13, 25, doi:10.1186/14712148-13-168 (2013).

10 Moller, A. P., Barnier, F. \& Mousseau, T. A. Ecosystems effects 25 years after Chernobyl: pollinators, fruit set and recruitment. Oecologia 170, 1155-1165, doi:10.1007/s00442-012-23740 (2012).

11 Moller, A. P., Bonisoli-Alquati, A. \& Mousseau, T. A. High frequency of albinism and tumours in free-living birds around Chernobyl. Mutat. Res. Genet. Toxicol. Environ. Mutagen. 757, 52-59, doi:10.1016/j.mrgentox.2013.04.019 (2013).

12 Moller, A. P. \& Mousseau, T. A. Reduced abundance of insects and spiders linked to radiation at Chernobyl 20 years after the accident. Biol. Lett. 5, 356-359, doi:10.1098/rsbl.2008.0778 (2009).

13 Nohara, C., Hiyama, A., Taira, W., Tanahara, A. \& Otaki, J. M. The biological impacts of ingested radioactive materials on the pale grass blue butterfly. Scientific Reports 4, 6, doi:10.1038/srep04946 (2014).

14 Nohara, C. et al. Ingestion of radioactively contaminated diets for two generations in the pale grass blue butterfly. BMC Evol. Biol. 14, 14, doi:10.1186/s12862-014-0193-0 (2014).

15 White, P. J. \& Broadley, M. R. Mechanisms of caesium uptake by plants. New Phytologist 147, 241-256, doi:10.1046/j.1469-8137.2000.00704.x (2000).

16 Shaw, G. Blockade by fertilizers of cesium and strontium uptake into crops- effects on the root uptake process. Science of the Total Environment 137, 119-133, doi:10.1016/00489697(93)90381-f (1993).

17 Zhu, Y. G. \& Smolders, E. Plant uptake of radiocaesium: a review of mechanisms, regulation and application. J. Exp. Bot. 51, 1635-1645, doi:10.1093/jexbot/51.351.1635 (2000).

18 Campbell, J. E. et al. The occurrence of Sr-90, I-131, and other radionuclides in milk - May, 1957, through April, 1958. American Journal of Public Health and the Nations Health 49, 225-235, doi:10.2105/ajph.49.2.225 (1959). 
Porter CR, Broadway JA, \& Kahn B. Methodology for surveillance of the food chain as conducted by the United States, in: Radionuclides in the Food Chain, eds Harley JH, Schmidt GD, \& Silini G. Springer, London (1988).

20 Broadway, J. A., Smith, J. M., Norwood, D. L. \& Porter, C. R. Estimates of radiation-dose and health risks to the United States population following the Chernobyl nuclear-plant accident. Health Physics 55, 533-539, doi:10.1097/00004032-198809000-00004 (1988).

21 Herrero-Latorre, C., Barciela-Garcia, J., Garcia-Martin, S. \& Pena-Crecente, R. M. The use of honeybees and honey as environmental bioindicators for metals and radionuclides: a review. Environ. Rev. 25, 463-480, doi:10.1139/er-2017-0029 (2017).

22 National Cancer Institute and Center for Disease Control and Prevention. Report on the feasibility of a study on the health consequences to the American Population from nuclear weapons tests conducted by the United States and Other Nations. https://www.cdc.gov/nceh/radiation/fallout/default.htm (2005).

23 Smith, D. B., Smith, S. M. \& Horton, J. D. History and evaluation of national-scale geochemical data sets for the United States. Geosci. Front. 4, 167-183, doi:10.1016/j.gsf.2012.07.002 (2013).

24 Simon, S. L., Bouville, A. \& Beck, H. L. The geographic distribution of radionuclide deposition across the continental US from atmospheric nuclear testing. Journal of Environmental Radioactivity 74, 91-105, doi:10.1016/j.jenvrad.2004.01.023 (2004). Chadwick, O. A., Derry, L. A., Vitousek, P. M., Huebert, B. J. \& Hedin, L. O. Changing sources of nutrients during four million years of ecosystem development. Nature 397, 491-497, doi:10.1038/17276 (1999).

26 Johnson, N. M., Likens, G. E., Bormann, F. H. \& Pierce, R. S. Rate of chemical weathering of silicate minerals in New Hampshire. Geochimica Et Cosmochimica Acta 32, 531-\&, doi:10.1016/0016-7037(68)90044-6 (1968).

27 Broadley, M. R. \& Willey, N. J. Differences in root uptake of radiocaesium by 30 plant taxa. Environmental Pollution 97, 11-15, doi:10.1016/s0269-7491(97)00090-0 (1997).

28 Robison, W. L. \& Stone, E. L. The effect of potassium on the uptake of 137Cs in food crops grown on coral soils: coconut at Bikini Atoll. Health physics 62, 496-511, doi:10.1097/00004032199206000-00002 (1992).

29 Fuller, A. J. et al. Caesium incorporation and retention in illite interlayers. Applied Clay Science 108, 128-134, doi:10.1016/j.clay.2015.02.008 (2015).

30 Pizzuto, J., Skalak, K., Pearson, A. \& Benthem, A. Active overbank deposition during the last century, South River, Virginia. Geomorphology 257, 164-178, doi:10.1016/j.geomorph.2016.01.006 (2016).

31 Radiological Health Data and Reports 1-15. U.S. Environmental Protection Agency Public Health Service, Washington, D.C. (1960-1974).

32 Salih, F. M., Pillay, A. E. \& Jayasekara, K. Measurement of cesium-137 in foodstuffs. J. Food Qual. 29, 295-304, doi:10.1111/j.1745-4557.2006.00063.x (2006).

33 Moller, A. P. \& Mousseau, T. A. The effects of natural variation in background radioactivity on humans, animals and other organisms. Biol. Rev. 88, 226-254, doi:10.1111/j.1469185X.2012.00249.x (2013).

34 Moller, A. P. \& Mousseau, T. A. Low-dose radiation, scientific scrutiny, and requirements for demonstrating effects. BMC Biol. 11, 3, doi:10.1186/1741-7007-11-92 (2013). Albright, M. K. Avoiding another Hiroshima. Science (New York, N.Y.) 369, 350-350, doi:10.1126/science.abd8622 (2020).

36 Potts, S. G. et al. Safeguarding pollinators and their values to human well-being. Nature 540, 220-229, doi:10.1038/nature20588 (2016). 


\section{Figures}

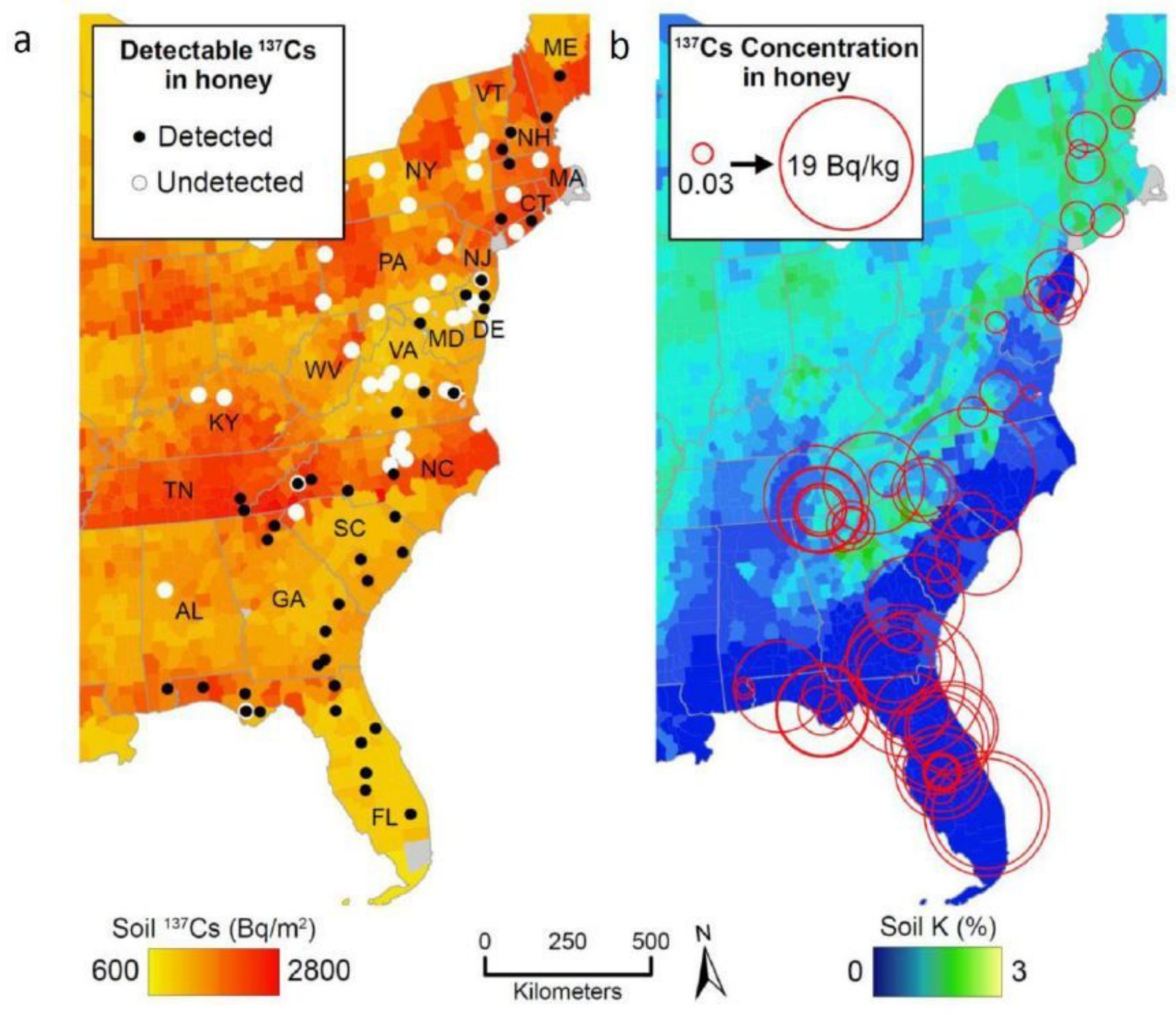

Figure 1

Distribution of 137Cs activities in honey in the eastern United States. (a) Detectable 137Cs in honey on a map with 20th century 137Cs deposition to soils determined at the county scale22,24 decay corrected to 2019. (b) Circles scaled logarithmically showing the relative magnitude of 137Cs in honey on a map with county mean soil potassium concentrations determined from airborne radiometric surveys 23 . Note: The designations employed and the presentation of the material on this map do not imply the expression of any opinion whatsoever on the part of Research Square concerning the legal status of any country, territory, city or area or of its authorities, or concerning the delimitation of its frontiers or boundaries. This map has been provided by the authors. 


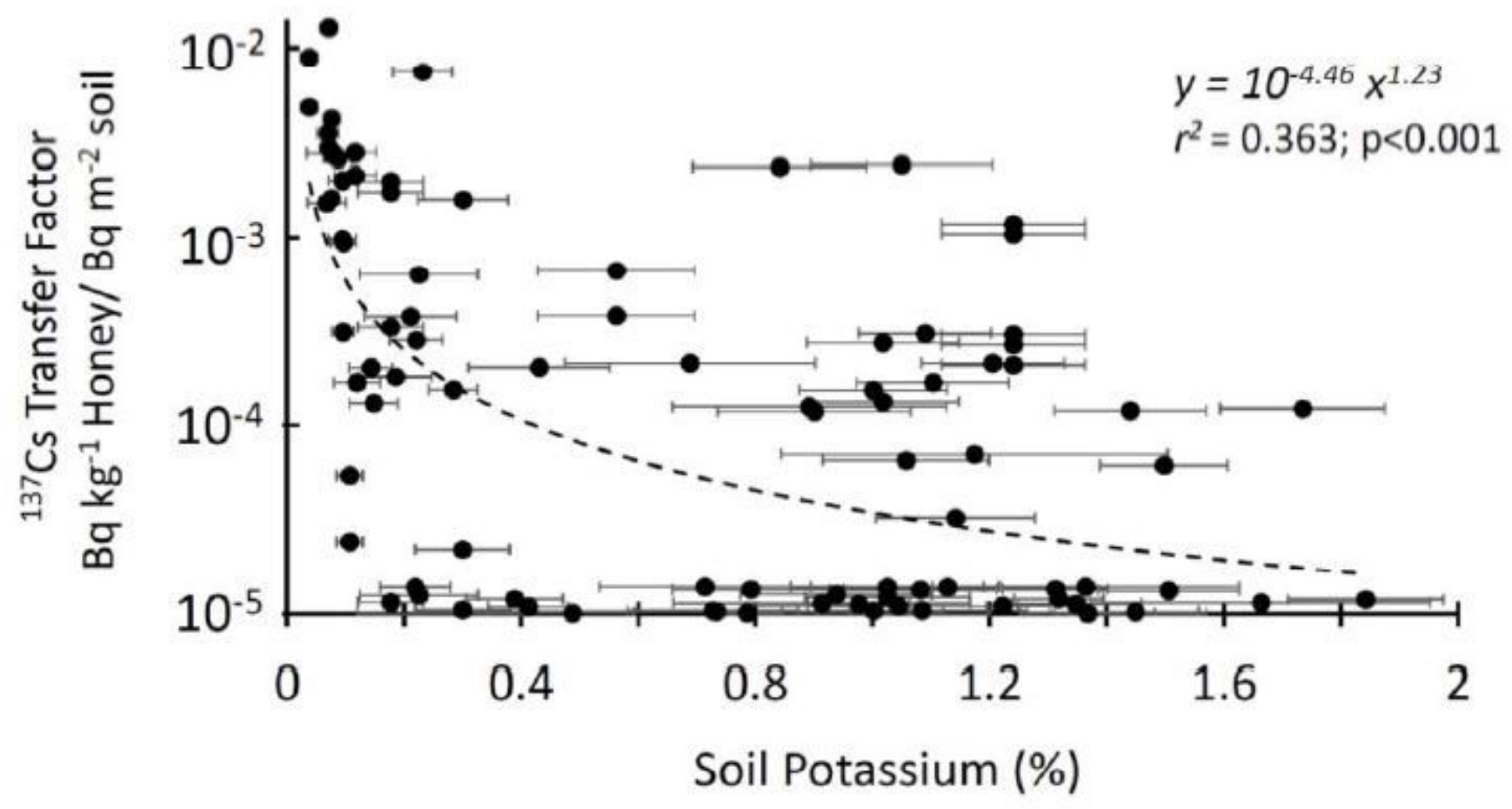

Figure 2

The transfer of 137Cs from soil to honey scales inversely with the average soil K of the county from which it is sourced. Uncertainty on this scaling is dominated by soil $\mathrm{K}$ variability within each county, shown here as one standard deviation of the mean. 


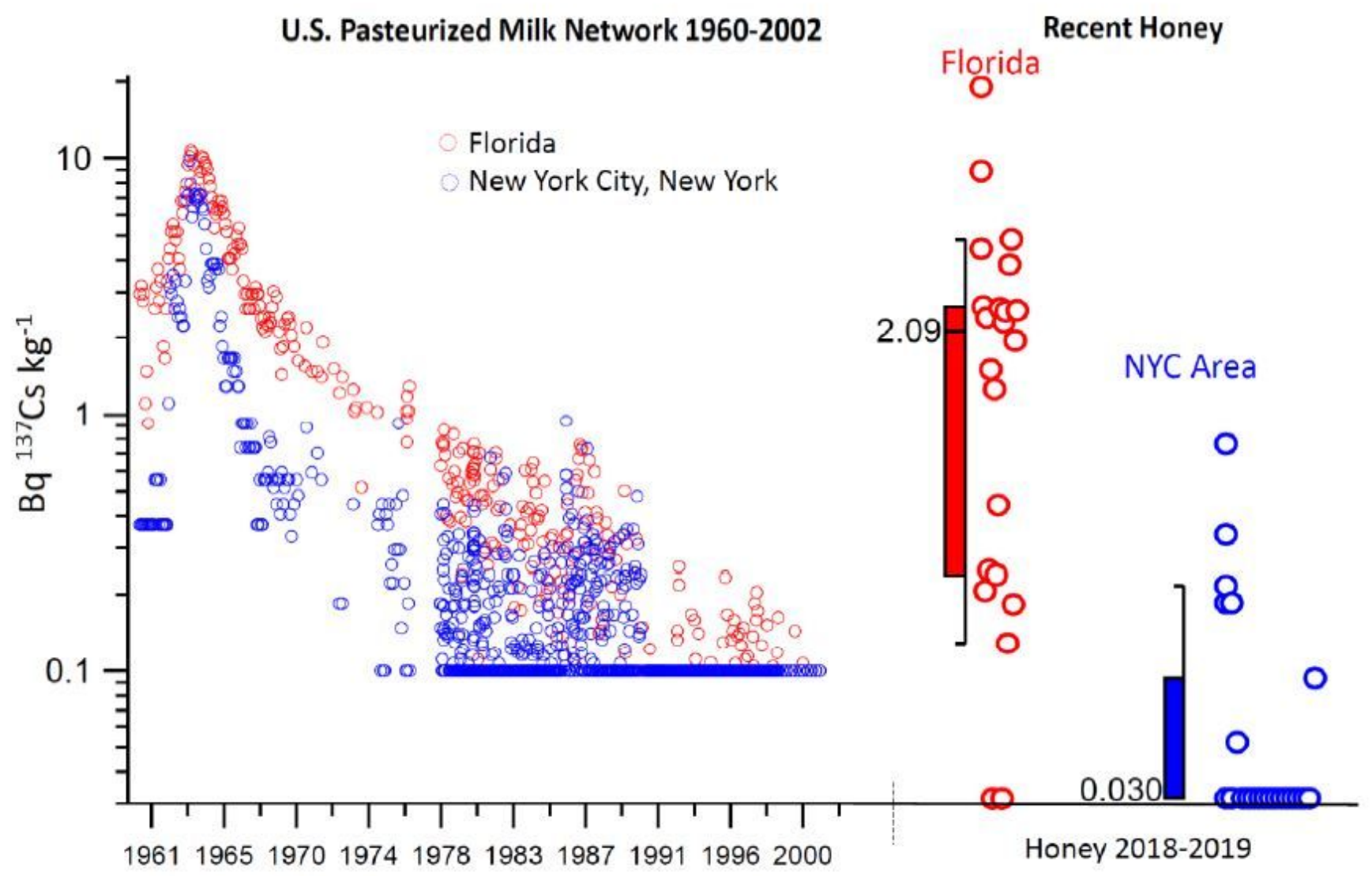

Figure 3

Monthly concentrations of $137 \mathrm{Cs}$ in milk measured by the U.S. Public Health Service radionuclide surveillance program from 1960 through 2002 in Tampa, Florida and New York City (NYC) compared with recent honey from Florida and the NYC area19,31. Honey 137Cs concentrations are shown on the same scale, median values for each area's honey are given; these two regions have significantly different magnitudes of 137Cs contamination (Mann-Whitney z score: 4.70, $p<0.001$ ) Detection limit is 0.1 and $0.03 \mathrm{~Bq} 137 \mathrm{Cs} \mathrm{kg-1}$ for the milk and honey data, respectively. Only 7 of the $21 \mathrm{NYC}$ area (includes CT, NJ) honeys had detectable 137Cs. 


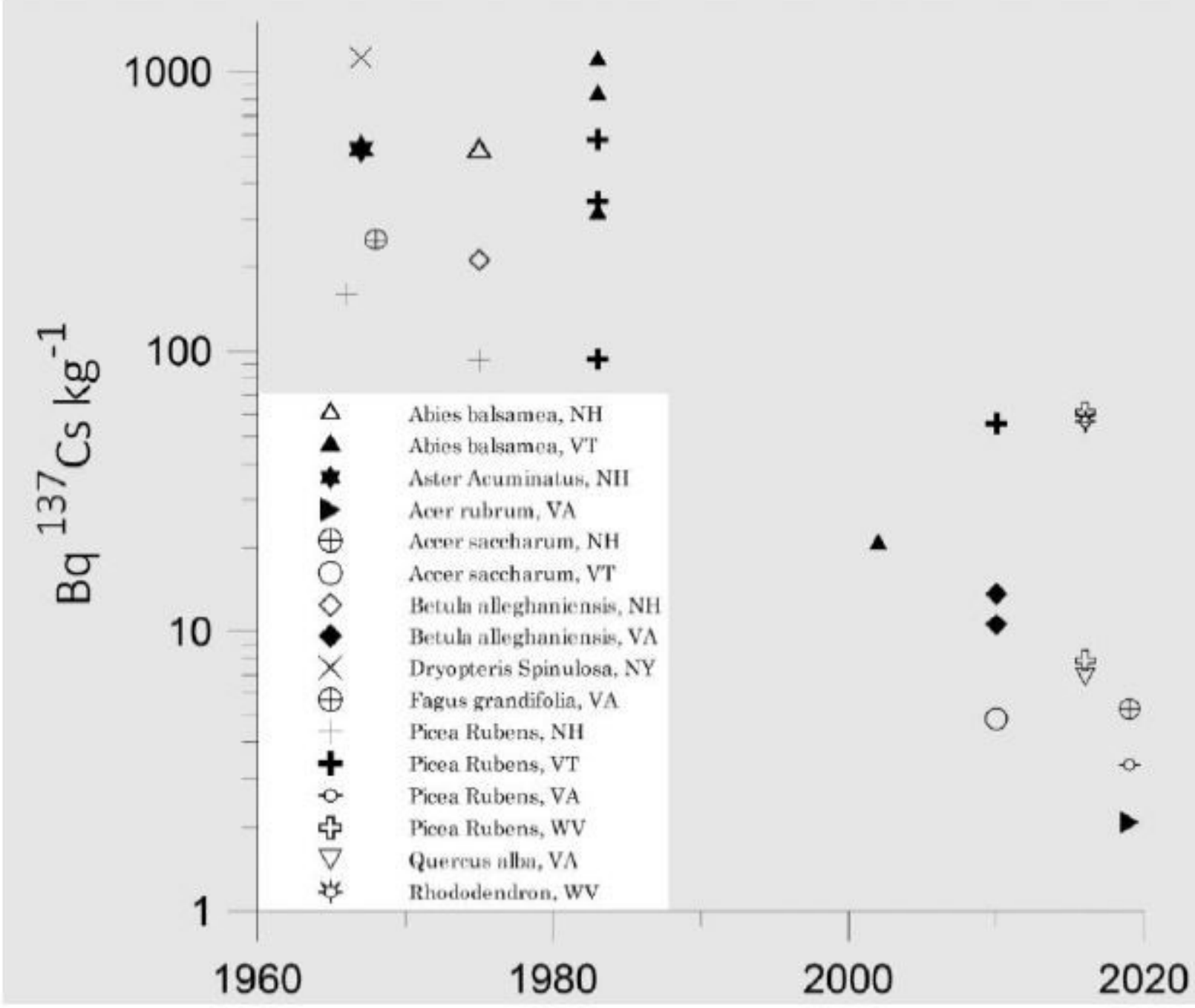

\section{Figure 4}

The 137Cs content of native vegetation (foliage) from the eastern U.S. using archives and more recent collections. Each symbol represents a single plant, and the species and state are given in the legend. 